\title{
IMPLEMENTASI METODE ANATITHYCAL PROSCESS (AHP) SISTEM PENDUKUNG KEPUTUSAN PEMILIHAN GURU BERPRESTASI PADA DINAS PENDIDIDIKAN KABUPATEN HALMAHERA UTARA
}

\section{IMPLEMENTATION OF ANALYTICAL PROCESS (AHP) METHODS OF DECISION SUPPORT SYSTEM FOR ACHIEVING TEACHERS ELECTION IN THE NORTH HALMAHERA DISTRICT DEPARTMENT OF EDUCATION}

\author{
Adelina Ibrahim ${ }^{1}$, Abdul Haris Muhammad ${ }^{2}$, Saiful Do. Abdullah ${ }^{3}$ \\ ${ }^{1,2,3}$ Fakultas Teknik, Program Studi Teknik Informatika \\ ${ }^{1,2}$ Universitas Muhammadiyah Maluku Utara, ${ }^{3}$ Universitas Khaiurn \\ Email: adelina_ibrahim@ummu.ac.id
}

\begin{abstract}
Abstrak
Sistem pendukung keputusan dalam dunia komputerisasi berkembang pesat, dengan sistem ini manusia dapat memperoleh informasi dalam mendukung keputusan. Penelitian ini membuat sebuah sistem pendukung keputusan yang dapat digunakan oleh Dinas Pendidikan Kabupaten Halmahera Utara dengan metode Analitical Hierarchy Process, sehingga dapat membantu pihak dinas pendidikan dalam memberikan suatu pendukung keputusan. Metode yang digunakan dalam sistem pendukung keputusan pada penelitian ini adalah metode Analytical Hierarchy Process (AHP). Metode ini mendukung penilaian kriteria dan pembobotan. Sistem ini mampu menampilkan alternatif berdasarkan hasil perhitungan metode AHP. Hasil perangkingan diurutkan dari hasil alternatif tertinggi ke hasil alternatif terendah. Sistem ini bermanfaat bagi pihak dinas pendidikan sebagai bahan pendukung keputusan dan acuan kebijakan untuk menentukan guru berprestasi berdasarkan kriteria yang ditentukan dan dapat membantu dinas pendidikan dalam mengambil keputusan yang relevan untuk memilih guru berprestasi menggunakan metode AHP, dengan harapan dapat meningkatkan kinerja dan prestasi guru yang lainnya.
\end{abstract}

Kata kunci : Sistem Pendukung Keputusan, Analytical Hierarchy Process, Guru Berprestasi.

\begin{abstract}
Decision support systems in the world of computerization are increasing; humans can obtain information to support decisions with this system. This research makes a decision support system that can be used by the North
\end{abstract}


Halmahera District Education Office with the Analytical Hierarchy Process method so that it can assist the education office in providing decision support. The method used in the decision support system in this study is the Analytical Hierarchy Process (AHP) method. This method supports criteria and weighting assessments. This system can present alternatives based on the calculation results of the AHP method. The ranking results are sorted from the highest alternative product to the lowest alternative product. This system is helpful for the education office as decision support material and a policy reference for determining outstanding teachers based on specified criteria and can assist the education office in making relevant decisions to select excellent teachers using the AHP method, with the hope of improving the performance and achievement of other teachers.

\section{Keywords: Decision Support System, Analytical Hierarchy Process, Outstanding Teacher.}

\section{PENDAHULUAN}

Guru adalah sosok manusia yang kehadiranya sangat diharapkan dan perannya sangat penting dalam pendidikan, sebagai sumber yang memiliki posisi dan mengasumsikan bagian yang signifikan dalam pendidikan. Pada saat semua orang berbicara terkait masalah pendidikan, guru harus dikaitkan dengan berbagai diskusi, Terutama terkait dengan masalah pendidikan formal yang ada pada sekolah. Menjadi Guru bukan hanya sebuah pekerjaan yang mudah akan tetapi menjadi Guru bergantung pada panggilan jiwa atau permintaan hati jelas tidak Sederhana karena lebih banyak dekat dengan siswanya. Apa yang menyebabkan siswa tidak selalu berada dikelas, mungkin para guru bertanya apa peyebabnya.

Sistem pendukung keputusan yaitu implemantasi teori-teori pelaksanaan pengambilan keputusan yang telah disajikan oleh ilmu-ilmu seperti riset operasi dan management sains, hal terpenting adalah jika sudah mencari Jawaban untuk masalah yang didapatkan harus ditentukan manualnya (untuk sebagian besar untuk mencari kualitas yang paling sedikit, terbesar, atau ideal), sekarang ini komputer menawarkan kemampuan untuk menyelesaikan masalah dalam jangka waktu yang cukup singkat. Dalam menentukan guru berprestasi akan menghadapi tantangan dan membutuhkan waktu cukup lama setiap kali dilakukan Secara manual sebab banyaknya jumlah guru serta kriteria yang dipakai dalam penilaian guru berprestasi harus sesuai yang diharapkan. 
Kriteria tersebut menjadi acuan untuk menentukan guru berprestasi berdasarkan kinerjanya. Sistem ini dirancang dan menggunakan metode Analythical Hierarchy Process (AHP) yang akan digunakan sebagai teori pembobotan dari setiap faktor dan kriteria yang ada.

\section{Rumusan Masalah}

Berdasarkan masalah ini dibutuhkan sebuah sebuah sistem pendukung keputusan untuk membantu pemilihan guru berprestasi agar lebih efisien. Kriteria tersebut menjadi acuan untuk menentukan guru berprestasi berdasarkan kinerjanya. Sistem ini dirancang dan menggunakan metode Analythical Hierarchy Process (AHP) yang akan digunakan sebagai teori pembobotan dari setiap proses dan kriteria yang ada. Rumusan Masalah Bagaimana Merancang Sebuah Sistem pemilihan guru berprestasi dan agar dapat membantu memberikan informasi tentang sistem pemilihan guru berprestasi di Dinas Pendidikan Kabupaten Halmahera Utara dengan mudah dan cepat.

\section{LANDASAN TEORI}

Sistem pendukung keputusan adalah merupakan sistem informasi yang bertujuan untuk membantu memecahkan masalah yang dihadapi dalam pemilihan guru berprestasi. Terdapat tiga tujuan dalam sistem pengambilan keputusan yaitu :
1. membantu manager dalam membuat keputusan memecahkan masalah semiterstruktur.

2. Mendukung penilaian manager tidak untuk mengantikanya.

3. Meningkatkan efektifitas manajer dalam pengambilan keputusan.

Tahap-tahap dalam pengambilan keputusan adalah sebagi berikut :

1. Kegiatan intelijen ini merupakan kegiatan mengamati lingkunag untuk mengatahui kondisikondisi yang perlu di perbaiki. Kegiatan ini merupakan tahapan dalam perkembagan cara berpikir. Untuk melakukan kegiatan intelijen ini dipelukan sebuahsistem informasi, dimana informasi yang diperlukn ini didapatkan dari kondisi internal maupun eksternal sehingga seorang manajer dapat mengambil keputusan dengan tepat.

2. Kegiatan merancang merupkan sebuah kegiatan untuk menemukan, mengembangkan, dan menganalisa berbagai alternatif tindakan yang mungkin untuk dilakukan tahap perancangan ini meliputu pengembangan dan menevaluasi serangkaian kegiatan alternatif. Perenungan mendasar telah dikenali oleh Simon dengan melengkapi tahap ini. 
3. Kegiatan memilih dan mengelah digunakan digunakan untuk memilih suatu tatanan kegiatan tertentu dari sedikit yang dapat diakses dan melakukan evaluasi terhadap kegiatan yang telah dipilih.

Tahapan metode Analisis hirarki proses $(A H P)$ yaitu sebagai berikut :

1. Mendefinisikan permasalahan dan penentuan tujuan. Jika AHP digunakan untuk memilih pilihan atau fokus pada pilihan lain, maka pada tahap ini dibuat pilihan

2. Menyusun masalah kedalaman sistem hierarki sehingga masalah yang membingungkan dapat dilihat dari sisi yang pasti dan dapat diukur.

3. Prioritas untuk setiap komponen sulit dalam sistem hierarki. Siklus ini menciptakan bobot atau komitmen komponen terhadap pencapaian tujuan sehingga komponen dengan bobot yang paling tinggi memiliki kebutuhan.

4. Kebutuhan dibuat dari kerangka kerja pemeriksaan berpasangan antara semua komponen pada tingkat hierarki yang serupa

Lakukan pengujian konsistensi korelasi antar komponen yang didapat di setiap level rantai tingkat hierarki.

a. Kriteria yang menjadi penentuan yaitu Pedagogik, Professional, Kepribadian, dan Sosial.

b. Menyusun kriteria-kriteria penentuan guru berprestasi dengan matrik perbandingan berpasangan. Masukan awal adalah menentukan nilai kriteria.

Tabel 1 Matrik perbandingan berpasangan

\begin{tabular}{|l|c|c|c|c|}
\hline \multicolumn{1}{|c|}{ Kriteria } & Pedagogik & Professional & Kepribadian & Sosial \\
\hline Pedagogik & 1 & 0,5 & 0,33 & 0,25 \\
\hline Professional & 2 & 1 & 0,50 & 0,20 \\
\hline Kepribadian & 3 & 2 & 1 & 0,3 \\
\hline Sosial & 4 & 5 & 4 & 1 \\
\hline
\end{tabular}

1. Jumlah elemen setiap kolom adalah:

Pedagogik: $1+2+3+4=10$

Professional: $0,5+1+2+5=8,5$

Kepribadian: $0,33+0,50+4=5,8$

Sosial: $0,25+0,20+0,3+1=1,7$

2. Menghitung matrik normalisasi pada kolom 1 dan baris 1 maka dapat di hitung sebagai berikut :

Tabel 2 Hasil matrik nilai kriteria

\begin{tabular}{|c|c|c|c|c|c|c|}
\hline Kintenia & Pedagogik & Professional & Kepribadian & Sosial & Jumlah & Priontas \\
\hline Pedagogik & $110=0,1$ & $0,58,5=0,06$ & $0,335,8=0,06$ & $0,251,7=0,15$ & 0,36 & $0,364=0,09(9 \%)$ \\
\hline Professional & $210=0,2$ & $18,5=0,12$ & $0,505,8=0,09$ & $0,201,7=0,12$ & 0,52 & $0,524=0,13(13 \%)$ \\
\hline Kepribadian & $310=0,3$ & $28,5=0,24$ & $15,8=0,17$ & $0,31,7=0,15$ & 0,85 & $0,854=0,21(21 \%)$ \\
\hline Sosial & $410=0,4$ & $58,5=0,59$ & $45,8=0,69$ & $11,7=0,59$ & 2.26 & $2.264=0.57(57 \%)$ \\
\hline
\end{tabular}

\section{METODE PENELITIAN}

\section{Analisis Kebutuhan Sistem}

Penelitian ini memiliki dua analisis kebutuhan sistem yakni Perangkat Lunak (software) dan 
Perangkat Keras (hardware) yang digunakan pada Dinas Pendidikan Kab. Halut. dalam menjalankan sistem yang di bangun memiliki kebutuhan satu unit komputer dengan spesifikasi sebagai berikut :

Perangkat Lunak (software) spesifikasi Perangkat sebagai berikut :

1. Database server

2. $P H P$

3. $Х A M P P$

4. OS (Operasionnal System)

Windows 7, 8, 10 atau yang lebih tinggi

Perangkat Keras (hardware) presifikasi Perangkat sebagai berikut :

1. Proccesor Intel Pentium $2,2 \mathrm{GHz}$

2. Memory (RAM) $2 G B$

3. Hard Disk $500 \mathrm{~GB}$

4. Monitor14 Inc, All Resolution

5. Keybord

6. Mouse

7. Printer

\section{Analisis sistem yang berjalan}

Berdasarkan penilitian yang dilakukan penulis di lokasi penelitian dalam mengamati penerapan sistem yang di gunakan maka, ada beberapa masalah yang menjadi perhatian bagi penulis yaitu:

1. Pemilihan Guru Berprestasi di Dinas Pendidikan Kab Halut masih secara manual.

2. Proses Pendaftaran masih dengan cara mengisi data formulir terlebih dahulu.
3. Perhitungan hasil rangking seleksi pemilihan guru berprestasi masih menggunakan MS Office Excel sehingga melambat pekerjaan.

\section{Analisis Sistem yang diusulkan}

Permasalahan dan hambatan yang dihadapi oleh Dinas Pendidikan Kabupaten Halmahera Utara khususnya pada bagian Seleksi Guru Berprestasi, maka dibutuhkan sebuah sistem baru yang dapat membantu menyelesaikan permasalahan yang terjadi. Sistem yang dibangun harus menggunakan teknologi komputer dengan aplikasi khusus sebagai sarana untuk mengatasi persoalan yang sering dihadapi, sistem yang terkomputerisasi dan berbasis internet memiliki banyak keunggulan, maka pembuatan sistem Pemilihan guru Berprestasi sangat diperlukan karena sistem computer memiliki keunggulan diantaranya, Sistem dapat bekerja lebih cepat dan memiliki tingkat ketelitian yang sangat tinggi. Dari analisis sistem yang berjalan, maka diusulkan sebuah sistem komputerisasi berbasis Web Pemilihan guru berprestasi yang diharapkan dapat memberikan kemudahan kepada pihak Dinas Pendidikan Kabupaten Halmahera utara sebagai Berikut. 


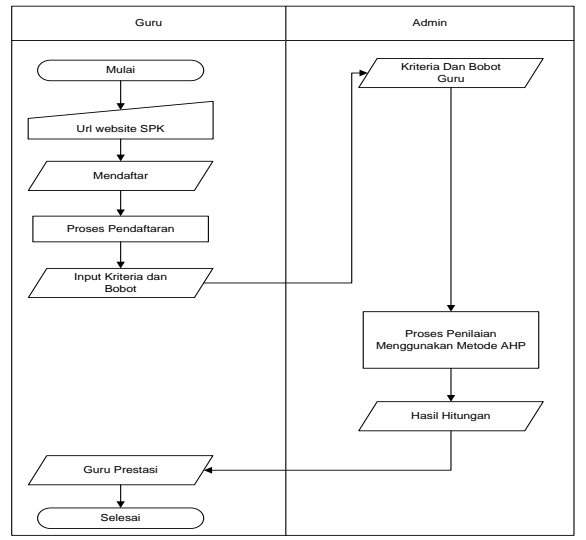

Gambar 1 . Sistem yang di usulkan

\section{Perancangan Sistem}

Perancangan sistem adalah membentuk sebuah sistem berdasarkan hasil analisis. Perancangan sistem bertujuan memberikan pemahaman serta gambaran kepada user.

Berdasarkan hasil yang didapat dalam analisis sistem kemudian dibuatlah perancangan sistemnya, antara lain, Data Flow Diagram (DFD), Entity Relantionship Diagram (ERD), Referential Integrity, dan Rancangan Menu Program.

Diagram konteks menjelaskan secara umum gambaran dari rancangan sistem yang akan dibuat. Proses keseluruhan sistem atau model dasar sistem secara garis besar digambarkan pada diagram konteks, Untuk lebih jelasnya lihat aliran data dari diagram konteks Sistem Pendukung Keputusan Pemilihan Guru Berprestasi di Dinas Pendidikan kabupaten Halmahera Utara Menggunakan Metode AHP seberikut:

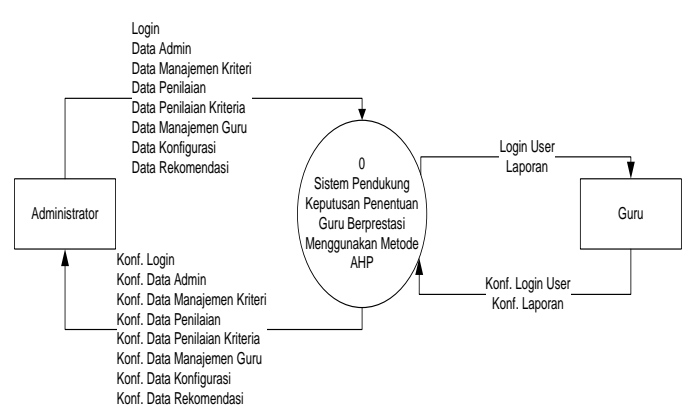

Gambar. 2 Diagram Konteks

ERD (Entity Relationship Diagram) adalah notasi yang digunakan untuk melakukan aktivitas pemodelan data. Atribut darimasing-masing objek data ditulis pada ERD dapat digambarkan dengan menggunakan deskripsi objek data. (Pressman).

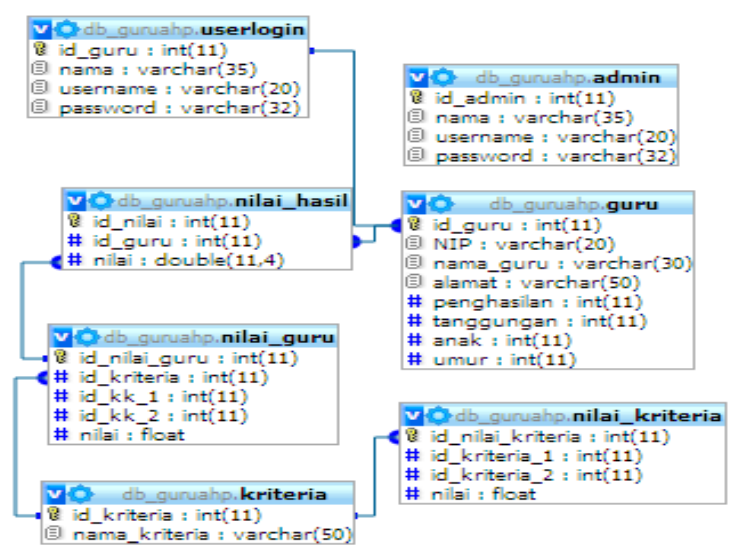

Gambar.3 Entity-Relationship Diagram

\section{IMPLEMENTASI SISTEM}

Tahapan implementasi merupakan tahapan untuk menguji kelayakan suatu sistem informasi yang selanjutnya dioperasikan 
sesuai dengan fungsi dan kelayakannya.

\section{Menu Utama}

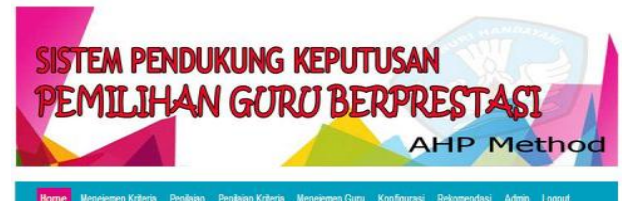

Stemut toung

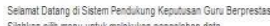

Gambar 4. Menu Utama

Halaman beranda merupakana halaman yang ditampilkan ketika user berhasil melakukan login ke sistem.

\section{Menu Penilan Kriteria}

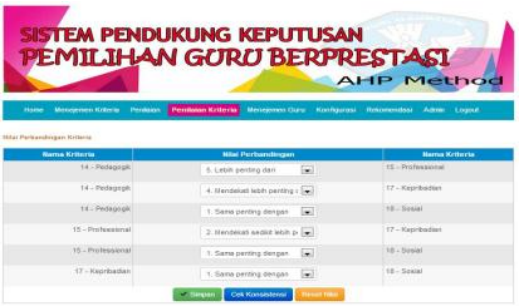

Gambar 5. Menu Penilaian Kritaria

$\begin{array}{lcr}\quad \text { Halaman } & \text { data } & \text { penilaian } \\ \text { merupakan } & \text { halaman } & \text { yang } \\ \text { menampilkan } & \text { data-data } & \text { nilai } \\ \text { perbandingan } & \text { guru yang telah dipilih } \\ \text { dan disimpan. } & & \end{array}$

\section{Menu Data Menejemen Guru}

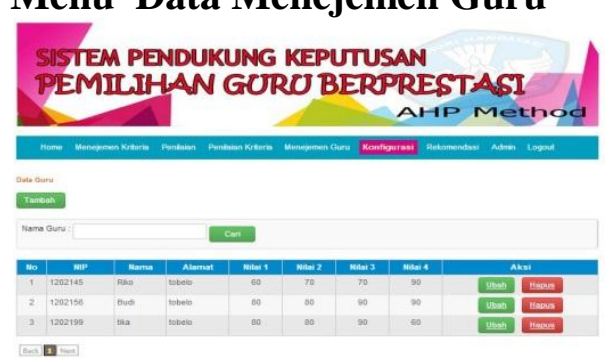

Gambar 6. Menu Menejemen Guru

Halaman data menejemen guru yaitu halaman yang menampilkan data akun login guru. Berikut gambar halaman data menejemen guru yaitu :

\section{Menu Data Konfigurasi}
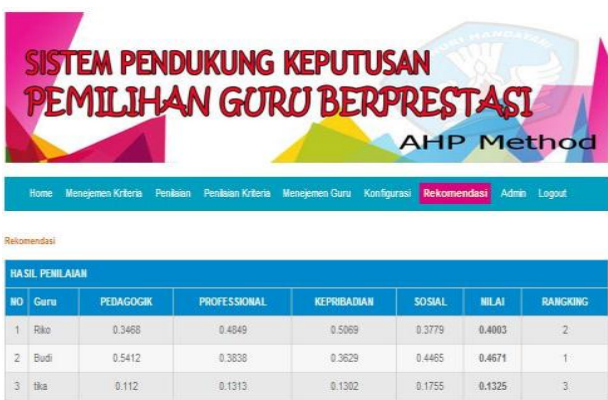

Gambar 7. Menu Data konfigurasi

Halaman konfigurasi merupakan halaman untuk melihat data nilai guru.

\section{Menu Data Rekomendasi}

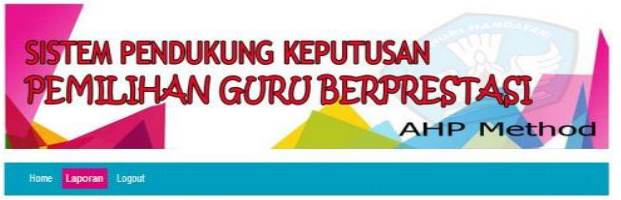

Gambar 8. Menu Rekomendasi

Halaman Rekomendasi merupakan halaman untuk melihat hasil nilai guru (Ranking). 


\section{KESIMPULAN}

Berdasarkan hasil implementasi dan konsep sistem pendukung keputusan pemilihan guru berprestasi dapa dinas pendidikan Kab. Halmahera Utara maka disimpulkan sebgai berikut:

1. Sistem Pengambilan Keputusan Diharapkan dapat memberikan memberikan kemudahan kepada Dinas Pendidikan Kab. Halut dalam proses pemilihan guru berprestasi.

2. Aplikasi ini sangat mudah dan dibangun dengan menggunakan metode Analythical Hierarchy Process memberikan alternatif penilaian yang baik.

\section{SARAN}

Berdasarkan kesimpulan diatas maka disarankan:

1. Untuk pengembangan lebih lanjut sistem ini dapat dikembangkan dengan menggunakan metode yang berbeda

2. Pendukung Keputusan Atau mengkombinasikan metode Analythical Hierarchy Process dengan metode lain agar dapat mengkover aturan metode dan melakukan update criteria beserta bobotnya

\section{DAFTAR PUSTAKA}

D. R. Bahari, E. Santoso, and S. Adinugroho, "Sistem Penentuan Guru Berprestasi Menggunakan Fuzzy-AnalyticHierarchy Process (FAHP) (Studi Kasus: SMA
Brawijaya Smart School), "Vol.2,No.5, pp.2095210, 2018.

G. Ginting, Fadlina, Mesran, A. P. U. Siahaan, and R. Rahim, "Technical Approach of TOPSIS in Decision Making," Int. J. Recent Trends Eng. Res., vol. 3, no. 8, pp.58-64, 2017.

H. Nurdiyanto and Heryanita Meilia, "Sistem Pendukung Keputusan Penentuan Prioritas Pengembangan Industri Kecil Dan Menegah di Lampung Tengah Menggunakan Analitical Hierarchy Process (AHP)," in Seminar Nasional Teknologi Informasi dan Multimedia 2016, 2016, no. February, pp. 1-7.

Jimmy Abdel Kadar, D Agustono, and Darmawan Napitupulu, "Optimization of Candidate Selection Using Naive Bayes: Case Study in Company $X$ Optimization of Candidate Selection Using Naive Bayes: Case Study in Company X," J. Phys. Conf. Ser., vol. 12, no. 1, 2016.

Jenita Puspita Angelina Pulu. "Sistem Pendukung Keputusan Penentuan Siswa Berprestasi Pada MAN 1 Haharu Mengunakan Metode Analitical Hierarchy Process" JATI (Jurnal Mahasiswa Teknik Informatika). Vol. 2 No. 2, September 2018 
Kementrian Penidikan dan

Kebudayaan. Pedoman Pemilihan

Guru Berprestasi Tingkat

Nasional. 2013.

S. Chakraborty and E. K. Zavadskas, "Applications of WASPS Method

in Manufacturing Decision

Making," Informatica, vol. 25, no.

1, pp. 1-20, 2014.

W. D Puspitasari and K. Ilmi "Sistem

Pendukung Keputusan Pemilihan

Dosen Berprestasi Menggunakan

Metode Analytichal Hiararchy

Process (AHP)“ in Jurnal

Antivirus, Vol. 10 no. 2, 2016, November, pp-1-5

Kusrini. Konsep dan Aplikasi Sistem

Pendukung Keputusan. 2010

Yogyakarta: Andi.

Kunz, Jeff. The Analytic Hierarchy

Process (AHP).2010 Eagle City

Hall. 